\title{
Correlation of increased numbers of tumor-infiltrating T regulatory, CD19 and CD8 T cells in well differentiated oral squamous cell carcinoma
}

\author{
Victor Angelo MONTALLI ${ }^{1}$ \\ Fabricio PASSADOR-SANTOS ${ }^{1}$ \\ Andresa Borges SOARES' \\ Elizabeth F. MARTINEZ ${ }^{1}$ \\ Denise B. R. RODRIGUES² \\ Vera Cavalcanti ARAUJO' \\ Marcelo Henrique NAPIMOGA ${ }^{3}$
}

\section{ABSTRACT}

Evidence from cancer patients suggests that increases in T-regulatory lymphocyte (Treg) activity may be associated with poor immune responses against tumor antigens, and contribute to immune dysfunction. Since there have been contradictory reports concerning the physiological roles of the Treg and inflammatory cells in the tumor microenvironment, the inflammatory cell influx was investigated for different malignancy grades of oral squamous cell carcinoma (OSCC). A total of 42 patients with OSCC were selected. Tumors were histologically graded as well, moderately, or poorly differentiated. Tissue microarrays were performed to immunohistochemically measure the expression of CD8, Foxp3, CD19, and IL-10. Significant statistical increases $(p<0.05)$ were observed in the numbers of Foxp3+ and CD8+ inflammatory cells, as well as in IL-10 expression, in the well differentiated tumors, compared to the poorly differentiated tumors. No differences between the three different histological grades were observed in the numbers of CD19+ cells. The relationship between the tumor grade and Treg and CD8 cell recruitment in patients with OSCC underlined the fact that the immune system is deregulated as a consequence of the disease.

Keywords: Inflammation. Oral cancer. T regulatory cell. Tumor.

\section{INTRODUCTION}

Oral squamous cell carcinoma (OSCC) represents more than $95 \%$ of all malignant neoplasia in the oral cavity and according to WHO are an estimated 529,000 new cases of cancers of the oral cavity and pharynx each year, and more than 300,000 deaths [1]. The mortality rate for this tumor is high, and overall 5 -year survival is less than $50 \%$ [2].

The expression of a range of immune system mediators and modulators, as well as the different activation states of the many cell types in the tumor microenvironment, can indicate in which direction the immunobalance is driven, and whether either tumorpromoting inflammation or antitumor immunity will develop $[3,4]$. In this context, CD4+CD25+Foxp3+ regulatory $T$ cells (Tregs) play a fundamental role in maintaining immunobalance. The Treg population is essential for the prevention of autoimmunity, and was first described as a subpopulation of CD4+ T cells in
1995 [5]. The immunoregulatory activities of these cells are mainly based on the secretion of suppressor cytokines, such as IL-10, TGF- $\beta$, and IL-35, that can directly inhibit the function of myeloid and activated $T$ cells [6].

Several previous studies have shown that the inhibition of Tregs results in the suppression of tumors $[7,8]$, so that high levels of Tregs are therefore associated with worse prognoses $[9,10]$. The frequency and function of Tregs with tumor suppressor phenotypes was significantly greater in patients with head and neck cancer, than in normal individuals $[11,12]$. In some cases, however, depending on the type of tumor, Treg infiltration in and around the tumor can be valuable [13]. To support this, it has been demonstrated that higher numbers of intratumoral Tregs in head and neck tumors were positively associated with better regional control of the tumor [14].

Although the prognostic value of histopathological grading is limited, it nonetheless

\footnotetext{
${ }^{1}$ Laboratory of Pathology, São Leopoldo Mandic Institute and Research Center. Campinas, SP, Brazil.

${ }^{2}$ Laboratory of Biopathology and Molecular Biology, University of Uberaba. Uberaba, MG, Brazil

${ }^{3}$ Laboratory of Immunology and Molecular Biology, São Leopoldo Mandic Institute and Research Center. Rua José Rocha Junqueira, 13, Campinas, SP, 13045-755, Brazil. Correspondência para / Correspondence to: MH NAPIMOGA. E-mail: <marcelo.napimoga@gmail.com>.

$\mathbf{v} \mathbf{v} \boldsymbol{\nabla}$

Como citar este artigo / How to cite this article

Montalli, Victor Angelo. Correlation of increased numbers of tumor-infiltrating T regulatory, CD19 and CD8 T cells in well differentiated oral squamous cell carcinoma. InterAm J Med Health. 2018;1(1):e201801004.
} 
offers a practical means of evaluating the degree of differentiation among tumors. The present study investigates lymphocyte infiltration in the tumor, as well as differences in the numbers of each invading lineage (especially Tregs), in well, moderately, and poorly differentiated OSCC.

\section{METHODS}

\section{Patients}

A total of 42 patients ( 34 males and 8 females; age range $23-88$, (mean \pm standard deviation $62.0 \pm 13.7$ years) diagnosed with oral squamous cell carcinoma (OSCC) were included in the study, using the archives of the Laboratory of Pathology, São Leopoldo Mandic Institute and Research Center (Campinas, Brazil). No patients underwent chemotherapy or radiation therapy prior to surgery. The clinicopathological characteristics of the patients are summarized in Table 1. Tumors were classified as well, moderately, or poorly differentiated, according to the World Health Organization (WHO) classification scheme based on histological grading. All of the tumor classifications were performed by the same examiner (F.P-S.), who was calibrated according to the proposed method. The study was approved by the Ethics Committee of the São Leopoldo Mandic Institute and Research Center (protocol number 2009/260), and informed consent forms were signed by all patients.

Table 1. Clinicopathological characteristics of OSCC.

\begin{tabular}{|c|c|c|c|}
\hline Case & Gender & Age & Tumor site \\
\hline 1 & $M$ & 84 & Tongue \\
\hline 2 & M & 62 & $\begin{array}{l}\text { Retromolar } \\
\text { trigone }\end{array}$ \\
\hline 3 & $M$ & 59 & Floor of mouth \\
\hline 4 & $\mathrm{~F}$ & 56 & Soft palate \\
\hline 5 & $M$ & 55 & Tongue \\
\hline 6 & $M$ & 64 & Floor of mouth \\
\hline 7 & $M$ & 56 & $\begin{array}{l}\text { Retromolar } \\
\text { trigone }\end{array}$ \\
\hline 8 & $M$ & 51 & Gingiva \\
\hline 9 & $M$ & 50 & Tongue \\
\hline 10 & $M$ & 42 & Tongue \\
\hline 11 & $M$ & 85 & Inferior lip \\
\hline 12 & $M$ & 88 & $\begin{array}{l}\text { Retromolar } \\
\text { trigone }\end{array}$ \\
\hline 13 & $M$ & 61 & Gingiva \\
\hline
\end{tabular}

\begin{tabular}{|c|c|c|c|}
\hline 14 & $\mathrm{~F}$ & 63 & Gingiva \\
\hline 15 & $\mathrm{~F}$ & 66 & Tongue \\
\hline 16 & $\mathrm{~F}$ & 64 & Tongue \\
\hline 17 & $\mathrm{~F}$ & 71 & Gingiva \\
\hline 18 & $\mathrm{M}$ & 75 & $\begin{array}{l}\text { Retromolar } \\
\text { trigone }\end{array}$ \\
\hline 19 & $\mathrm{~F}$ & 67 & Inferior lip \\
\hline 20 & $M$ & 56 & Floor of mouth \\
\hline 21 & $\mathrm{M}$ & 60 & Floor of mouth \\
\hline 22 & $M$ & 54 & Tongue \\
\hline 23 & $\mathrm{M}$ & 73 & Floor of mouth \\
\hline 24 & $M$ & N/A & Tongue \\
\hline 25 & $M$ & N/A & $\begin{array}{l}\text { Retromolar } \\
\text { trigone }\end{array}$ \\
\hline 26 & $\mathrm{M}$ & 60 & Floor of mouth \\
\hline 27 & $M$ & 71 & N/A \\
\hline 28 & $M$ & 46 & Inferior lip \\
\hline 29 & $M$ & 39 & $\begin{array}{l}\text { Retromolar } \\
\text { trigone }\end{array}$ \\
\hline 30 & $M$ & 50 & Tongue \\
\hline 31 & $\mathrm{M}$ & 56 & Inferior lip \\
\hline 32 & $M$ & 63 & Tongue \\
\hline 33 & $M$ & 53 & $\begin{array}{l}\text { Retromolar } \\
\text { trigone }\end{array}$ \\
\hline 34 & $M$ & 82 & Floor of mouth \\
\hline 35 & $\mathrm{~F}$ & 48 & N/A \\
\hline 36 & $\mathrm{M}$ & $\mathrm{N} / \mathrm{A}$ & Floor of mouth \\
\hline 37 & $M$ & 70 & Tongue \\
\hline 38 & $M$ & 73 & Inferior lip \\
\hline 39 & $M$ & 52 & Floor of mouth \\
\hline 40 & $\mathrm{~F}$ & 32 & Gingiva \\
\hline 41 & $M$ & 69 & Tongue trigone \\
\hline 42 & $M$ & 58 & Floor of mouth \\
\hline
\end{tabular}

Note: N/A: not available; M: male; F: female.

\section{Tissue microarrays}

Samples were selected for tissue microarray (TMA) evaluation of the expression of CD19, CD8, Foxp3, and IL-10, using an immunohistochemical method (Santa Cruz Biotechnology, Santa Cruz, CA, USA). Representative sections of the tumors were obtained using two $3 \mathrm{~mm}$ core punches (Tissue-Tek Quick-Ray TM Tissue Microarray System, Sakura, USA). All punches included the inflammatory microenvironment of the tumors, and avoided necrotic or hemorrhagic areas. The selected cores were placed into TMA receptor blocks. $3 \mu \mathrm{m}$ thickness sections were used for the immunohistochemical analyses. 


\section{Immunohistochemistry}

For immunohistochemical staining, sections from each paraffin block were deparaffinized and hydrated, and endogenous peroxidase activity was quenched by immersion of the slides in 3\% hydrogen peroxide. Antigen retrieval (AR) was achieved by boiling the slides in a steamer immersed in citrate buffer $(\mathrm{pH}$ 6.0). The sections were subsequently incubated at $4{ }^{\circ} \mathrm{C}$ with the primary antibody for CD19, CD8, Foxp3, and IL-10, and then with the Advance System (DAKO S.A., Denmark) for 1 hour at $37^{\circ} \mathrm{C}$. The sections were stained for 5 minutes at $37{ }^{\circ} \mathrm{C}$ with 3,3'-diaminobenzidine tetrahydrochloride (DAB), and counter-stained with hematoxylin. A negative control was obtained by omitting the primary antibody, and gingival tissue from an individual with chronic periodontitis was used as a positive control. After the staining procedures, the tissue was observed using an Axioskop 2 microscope (Carl Zeiss Microlmaging GmbH, Germany). The number of immunostained cells in a $1 \mathrm{~mm} 2$ grid square was counted twice, at x100 magnification, by the same trained, calibrated, and blinded examiner (V.A.M.). Intra-class reproducibility of the number of positive cells was $\geq 90 \%$.

\section{Statistical analysis}

The statistical analysis was performed using the Prism 6.0 program (Graphpad Software, La Jolla, (A, USA). The data were first examined for normality using the Kolmogorov-Smirnov test, and the data that achieved normality were analyzed using ANOVA and the post-hoc Tukey test. The level of significance was set at $5 \%$.

\section{RESULTS}

\section{Immunohistochemical analysis}

The positive staining of the OSCC tumor inflammatory markers was evaluated for the three different tumor grades. The well differentiated tumors presented values for CD8+ (Figure 1B), Foxp3+ (Figure 1C), and IL-10 expression (Figure 1D) that were significantly higher $(p<0.05)$ than the values obtained for the poorly differentiated tumors. In contrast, no statistical differences among the tumor grades were observed for CD19+ cells (Figure 1A). Representative images of each marker from well and poorly differentiated groups are shown in Figure 2.

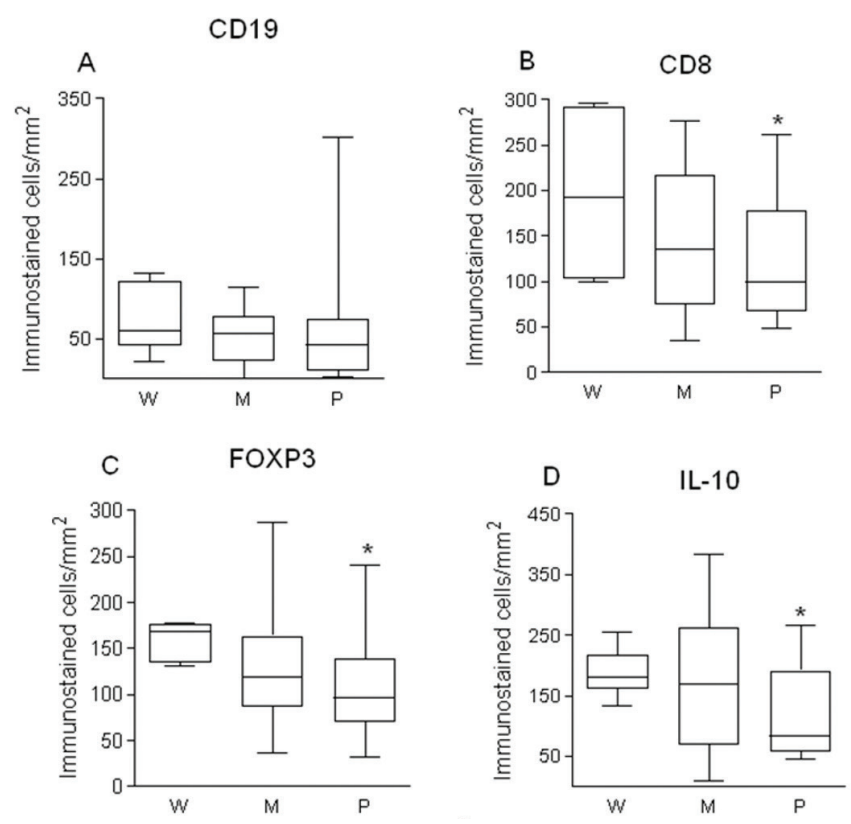

Figure 1. Numbers of immunostained cells/mm2: (A) CD19+, (B) CD8+, (C) Foxp3+, and (D) IL-10+, from well differentiated (W), moderately differentiated (M) and poorly differentiated $(P)$ tumors. The values are expressed as mean S.D. The symbol * indicates a statistically significant difference between well and poorly differentiated tumors.

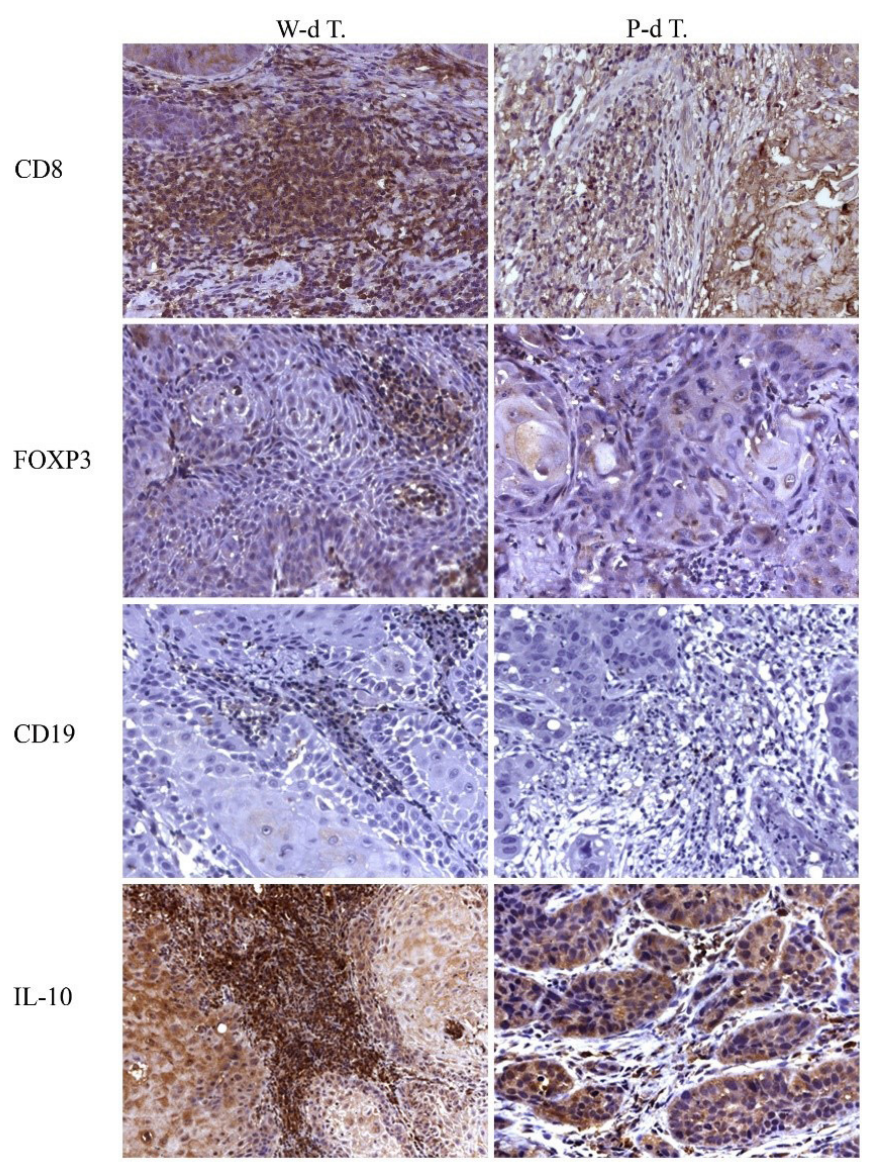

Figure 1. Representative photomicrographs of tumor-infiltrating lymphocytes and IL10 expression in oral squamous cell carcinoma, for well differentiated (W-d $\mathrm{T})$ and poorly differentiated (P-d T) tumors. 


\section{DISCUSSION}

Oral squamous cell carcinoma is the 10th most common cancer worldwide. Despite advances in treatment, the five-year disease-free survival rate has not improved in the past 30 years. New information on factors including the identity and role of lymphocyte subpopulations could help to guide methods of treatment.

The results of the present work revealed higher CD8+, Foxp3+, and IL-10 in well differentiated tumors than in poorly differentiated tumors. Although the presence of infiltrating leukocytes has been observed in the tumor microenvironment since the 19th century, it is only recently that the importance of the inflammatory infiltrate in tumorigenesis has been recognized [15].

The tumoral tissue is infiltrated to varying degrees by immune cells, suggesting a host immune response against cancer cells. There are conflicting reports concerning the relationship of inflammation with cancer, some of which suggest a pro-tumorigenic action [15]. On the other hand, there is evidence that the presence of anti-tumor inflammation is important for the control of tumor growth, an example being the intense chronic inflammatory infiltration observed in lung and colorectal cancers carcinomas, which is associated with a favorable prognosis. Cancer cells represent an "altered self", and express "non-self" antigens in the context of stress and danger signals that can promote antigen presentation $[15,16]$. Thus, even growing tumors may be subject to immunosurveillance and killing by activated $\mathrm{T}, \mathrm{B}$, and NK cells $[16,17]$.

It seems that the role played by inflammation, whether pro- or anti-tumorigenic, is also dependent on the type of tumor and the site and microenvironment where it occurs. Although the absolute number of peripheral blood lymphocytes decreases in many patients with breast cancer [18], the quantity of functionally suppressive CD4+CD25+ regulatory $T$ cells has been reported to increase in the peripheral blood, as well as in the tumor microenvironment [19]. Interestingly, increased circulatory Treg cells and IL-10 have been reported in patients with head and neck squamous cell carcinoma. The increase in IL-10 was positively correlated with shorter disease-free survival in patients with laryngeal or pharyngeal cancer, but not oral tumors [20]. These observations highlight the fact that the tumor microenvironment may exert a crucial influence on inflammation activity.

The present data show that there were significantly higher numbers of Treg, CD19+, and CD8+ T cells in tumors that were histologically well differentiated, compared to poorly differentiated tumors. Immunosurveillance and tumor-promoting inflammation can therefore coexist, even in the same tumor, as previously described [21]. The reason for this is not clear and deserves further investigation, although the finding suggests that tumor grade may have to be taken into consideration when interpreting data on tissue infiltrate cells in head and neck cancer. In addition, previous work has shown that an early genetic event, which is necessary and sufficient for the development of a human tumor, directly promotes the build-up of an inflammatory microenvironment [22]. It is noteworthy that CD8+ T lymphocytes are very important cytotoxic anti-cancer cells, and that reduced numbers of nest and stromal CD8 T cells have been associated with decreased survival time in patients with OSCC [23]. In addition, higher numbers of CD8+ within the invasive tumor have been found to lead to improved survival rates, suggesting that "more is better". Elevated densities of CD8+ cytotoxic T-lymphocyte infiltrate were associated with stage T1, while no patients with such early-stage tumors presented low densities. In patients that did not relapse, the density of CD8 infiltrates was inversely correlated with $T$ stage. In contrast, in patients where the tumor recurred, the number of CD8 cells was low, regardless of the T-stage of the tumor [24].

An explanation is required for the concomitant increases in the numbers of inflammatory cells (CD8 and CD19) and regulatory $T$ cells, in well differentiated cancer. Treg cells specifically regulate the activation, proliferation, and effector function of conventional T cells, determining the outcome of immunological conditions ranging from infectious diseases to immunopathology and autoimmunity [6, 25-27]. It is possible that in these environments, Treg cells are more crucial for limiting inflammation, and consequently for decreasing some of the factors important for tumor growth and survival $[28,29]$, which is favorable for tumor control. It has been reported that higher numbers of Tregs within the tissues of gastric [30], colorectal [31], and anal tumors [32] appears to be beneficial. Furthermore, according to the new concept called immunoediting, cancer cells constantly edit and modulate the host antitumor immune response, while the host immune response shapes tumor immunogenicity and clonal selection. During this process, the balance between antitumor and tumor-promoting immunity can be tilted in favor of tumor growth. 
Thus, equilibrium between tumor growth and immune destruction should be maintained before a tumor undergoes immune escape $[4,17,33]$.

It has been demonstrated that intratumoral Treg infiltration by itself does not have an impact on tumor control or survival rates [24]. Interestingly, it has been observed that prior to initiation of treatment, patients diagnosed with head and neck squamous cell carcinoma (HNSCC) had significantly higher percentages of CD4+CD25high Treg cells, compared to normal controls. Furthermore, after removal of the HNSCC tumor mass, the prevalence of CD4+CD25high Treg cells significantly increased above pre-treatment levels [20]. In another study, patients with OSCC and low Foxp3 had survival rates that were significantly lower than those of patients with high Foxp3, and there was no correlation between Foxp3 status and TNM classification, suggesting that Treg cells did not influence the progression of cancer [34]. Although it has been previously reported that higher Treg infiltration was correlated with a poor prognosis [12], the current results do not support this hypothesis, because high Foxp3 expression was found in the well differentiated tumors, which theoretically had a better prognosis than the poorly differentiated tumors. In contrast to the present results, in another previous study it was shown that there was significantly lower expression of FoxP3+ Treg cells in well differentiated OSCC, compared to moderately and poorly differentiated tumors [35].

The contradictory results reported in the literature could be explained, at least in part, by the fact that the histological tumor grade was not taken into consideration in the studies cited above $[12,34]$. Despite its limitations, the present findings indicate that histological grading can be an important tool for use in determining immunological status.

In summary, the relationship between the tumor grade and the recruitment of Treg and CD8 cells in patients with OSCC underlines the fact that the immune system is deregulated in individuals with cancer. Additional studies are required to elucidate the importance of higher numbers of inflammatory cells, including Treg cells, in well differentiated OSCC.

\section{REFERENCES}

1. Sloan P, Gale N, Hunter K, Lingen M, Nylander K, Reibel J, Salo $\mathrm{T}$, Zain RB. Malignant surface epithelial tumours. In: WHO Classification of Head and Neck Tumours. 4th ed. Lyon: IARC; 2017.
2. Sarode GS, Sarode SC, Maniyar N, Anand R, Patil S (2017). Oral cancer databases: A comprehensive review. J Oral Pathol Med. 2017 Nov 29. doi: 10.1111/jop.12667

3. Lin WW, Karin M. A cytokine-mediated link between innate immunity, inflammation, and cancer. J Clin Invest. 2007:117:1175-1183.

4. Zinger A, Cho WC, Ben-Yehuda A. Cancer and Aging - the Inflammatory Connection. Aging Dis. 2017;8:611-627.

5. Sakaguchi S, Sakaguchi N, Asano M, Itoh M, Toda M. Immunologic self-tolerance maintained by activated $T$ cells expressing IL-2 receptor alpha-chains (CD25). Breakdown of a single mechanism of self-tolerance causes various autoimmune diseases. J Immunol. 1995; 155:1151-1164.

6. Faria BA, Silva $\mathrm{SM}$, Abreu $\mathrm{MTCL}$, Napimoga $\mathrm{MH}$. T regulatory lymphocytes action in transplants. Rev Bras Hematol Hemoter. 2008;30:309-315.

7. Zhou Q, Bucher C, Munger ME, Highfill SL, Tolar J, Munn DH, et al. Depletion of endogenous tumor-associated regulatory $T$ cells improves the efficacy of adoptive cytotoxic T-cell immunotherapy in murine acute myeloid leukemia. Blood. 2009;114:3793-3802.

8. Hatam LJ, Devoti JA, Rosenthal DW, Lam F, Abramson AL, Steinberg BM, et al. Immune suppression in premalignant respiratory papillomas: enriched functional CD4+Foxp3+ regulatory T cells and PD-1/PD-L1/L2 expression. Clin Cancer Res. 2012;18:1925-1935.

9. Zhou J, Ding T, Pan W, Zhu LY, Li L, Zheng L. Increased intratumoral regulatory $T$ cells are related to intratumoral macrophages and poor prognosis in hepatocellular carcinoma patients. Int J Cancer. 2009;125:1640-1648.

10. Kobayashi N, Hiraoka N, Yamagami W, Ojima H, Kanai $Y$, Kosuge $T$, et al. FOXP3+ regulatory $T$ cells affect the development and progression of hepatocarcinogenesis. Clin Cancer Res. 2007;13:902-911.

11. Strauss L, Bergmann C, Gooding W, Johnson JT, Whiteside TL. The frequency and suppressor function of CD4+CD25highFoxp3+ T cells in the circulation of patients with squamous cell carcinoma of the head and neck. Clin Cancer Res. 2007;13:6301-6311.

12. Gasparoto TH, de Souza Malaspina TS, Benevides L, de Melo EJ $\mathrm{Jr}$, Costa MR, et al. Patients with oral squamous cell carcinoma are characterized by increased frequency of suppressive regulatory $T$ cells in the blood and tumor microenvironment. Cancer Immunol Immunother. 2010;59:819-828.

13. Wilke CM, Wu K, Zhao E, Wang G, Zou W. Prognostic significance of regulatory $\mathrm{T}$ cells in tumor. Int J Cancer. 2010;127:748-758.

14. Badoual C, Hans S, Rodriguez J, Peyrard S, Klein C, Agueznay $\mathrm{Nel} \mathrm{H}$, et al. Prognostic value of tumor-infiltrating CD4+ T-cell subpopulations in head and neck cancers. Clin Cancer Res. 2006:12:465-472.

15. Gu J, Liu Y, Xie B, Ye P, Huang J, Lu Z. Roles of toll-like receptors: From inflammation to lung cancer progression. Biomed Rep. 2018;8:126-132. 
16. Gao JF, Arbman G, Wadhra TI, Zhang H, Sun XF. Relationships of tumor inflammatory infiltration and necrosis with microsatellite instability in colorectal cancers. World J Gastroenterol. 2005; 11:2179-2183.

17. Dunn GP, Old LJ, Schreiber RD. The immunobiology of cancer immunosurveillance and immunoediting. Immunity. 2004;21:137-148.

18. de Jesus Leite MAF, Puga GM, Arantes FJ, Oliveira CJF, Cunha LM, Bortolini MJS, et al. Effects of combined and resistance training on the inflammatory profile in breast cancer survivors: a systematic review. Complement Ther Med. 2018;36:73-81.

19. Wolf AM, Wolf D, Steurer M, Gastl G, Gunsilius E, GrubeckLoebenstein B. Increase of regulatory $T$ cells in the peripheral blood of cancer patients. Clin Cancer Res. 2003;9:606-612.

20. Alhamarneh O, Agada F, Madden L, Stafford N, Greenman J. Serum IL10 and circulating CD4(+) CD25(high) regulatory T cell numbers as predictors of clinical outcome and survival in patients with head and neck squamous cell carcinoma. Head Neck. 2011;33:415-423.

21. Bui JD, Schreiber RD. Cancer immunosurveillance, immunoediting and inflammation: independent or interdependent processes? Curr Opin Immunol. 2007;19:203208.

22. Borrello MG, Alberti L, Fischer A, Degl'innocenti D, Ferrario C, Gariboldi $\mathrm{M}$, et al. Induction of a proinflammatory program in normal human thyrocytes by the RET/PTC1 oncogene. Proc Natl Acad Sci. 2005;102:14825-14830.

23. Watanabe $Y$, Katou F, Ohtani H, Nakayama T, Yoshie O, Hashimoto K. Tumor-infiltrating lymphocytes, particularly the balance between CD8(+) T cells and CCR4(+) regulatory T cells, affect the survival of patients with oral squamous cell carcinoma. Oral Surg Oral Med Oral Pathol Oral Radiol Endod. 2010;109:744-752.

24. Distel LV, Fickenscher R, Dietel K, Hung A, Iro H, Zenk J, et al. Tumour infiltrating lymphocytes in squamous cell carcinoma of the oro- and hypopharynx: prognostic impact may depend on type of treatment and stage of disease. Oral Oncol. 2009;45:e167-74.

25. Sakaguchi S, Sakaguchi N, Shimizu J, Yamazaki S, Sakihama $\mathrm{T}$, Itoh $\mathrm{M}$, et al. Immunologic tolerance maintained by CD25+CD4+ regulatory T cells: their common role in controlling autoimmunity, tumor immunity, and transplantation tolerance Immunol Rev. 2001;182:18-32.

26. Belkaid Y, Piccirillo CA, Mendez S, Shevach EM, Sacks DL. CD4+CD25+ regulatory $T$ cells control Leishmania major persistence and immunity. Nature. 2002;420:502-507.

27. Shevach EM. CD4+CD25+ suppressor T cells: more questions than answers. Nat Rev Immunol. 2002:2:389-400.

28. Coussens LM, Werb Z. Inflammation and cancer. Nature. 2002;420:860-867

29. Mantovani A, Allavena P, Sica A, Balkwill F. Cancer-related inflammation. Nature. 2008;454:436-444.

30. Haas $M$, Dimmler A, Hohenberger $W$, Grabenbauer GG, Niedobitek G, Distel LV. Stromal regulatory T-cells are associated with a favourable prognosis in gastric cancer of the cardia. BMC Gastroenterol. 2009;9:65.

31. Salama P, Phillips M, Grieu F, Morris M, Zeps N, Joseph $D$, et al. Tumor-infiltrating FOXP3 $+T$ regulatory cells show strong prognostic significance in colorectal cancer. J Clin Oncol. 2009;27:186-192.

32. Grabenbauer GG, Lahmer G, Distel L, Niedobitek G. Tumorinfiltrating cytotoxic $T$ cells but not regulatory $T$ cells predict outcome in anal squamous cell carcinoma. Clin Cancer Res. 2006;12:3355-3360.

33. Koebel CM, Vermi W, Swann JB, Zerafa N, Rodig SJ, Old LJ, et al. Adaptive immunity maintains occult cancer in an equilibrium state. Nature. 2007;450:903-907.

34. Yoshioka T, Miyamoto M, Cho $Y$, Ishikawa K, Tsuchikawa T, Kadoya $\mathrm{M}$, et al. Infiltrating regulatory $\mathrm{T}$ cell numbers is not a factor to predict patient's survival in oesophageal squamous cell carcinoma. Br J Cancer. 2008;98:1258-1263.

35. Al-Qahtani D, Anil S, Rajendran R. Tumour infiltrating CD25+ FoxP3+ regulatory $T$ cells (Tregs) relate to tumour grade and stromal inflammation in oral squamous cell carcinoma. J Oral Pathol Med. 2011;40:636-642. 